\title{
Variability of RNA Quality Extracted from Biofilms of Foodborne Pathogens Using Different Kits Impacts mRNA Quantification by qPCR
}

\author{
Angela França $\cdot$ Joana C. Bento $\cdot$ Nuno Cerca
}

Received: 8 January 2012/ Accepted: 27 March 2012/Published online: 24 April 2012

(C) Springer Science+Business Media, LLC 2012

\begin{abstract}
The biofilm formation by foodborne pathogens is known to increase the problem related with surface disinfection procedure in the food processing environment and consequent transmission of these pathogens into the population. Messenger RNA has been increasingly used to understand the action and the consequences of disinfectants in the virulence on such biofilms. RNA quality is an important requirement for any RNA-based analysis since the quality can impair the mRNA quantification. Therefore, we evaluated five different RNA extraction kits using biofilms of the foodborne pathogens Listeria monocytogenes, Escherichia coli, and Salmonella enterica. The five kits yielded RNA with different quantities and qualities. While for E. coli the variability of RNA quality did not affect the quantification of mRNA, the same was not true for L. monocytogenes or S. enterica. Therefore, our results indicate that not all kits are suitable for RNA extraction from bacterial biofilms, and thus, the selection of RNA extraction kit is crucial to obtain accurate and meaningful mRNA quantification.
\end{abstract}

\section{Introduction}

Foodborne pathogens are responsible for, approximately, 9.5 million illnesses, 55,961 hospitalizations, and 1,351 deaths in the United States [21]. Within the known foodborne pathogens, Escherichia coli, Salmonella enterica, and Listeria monocytogenes are among the most common

A. França · J. C. Bento · N. Cerca $(\bowtie)$

Centre of Biological Engineering, IBB-Institute for

Biotechnology and Bioengineering, University of Minho,

Campus de Gualtar, 4710-057 Braga, Portugal

e-mail: nunocerca@ceb.uminho.pt
[21]. Surface contamination in food processing environment by these bacteria, and consequent inadequate or ineffective disinfection procedure is one of the direct causes of food spoilage and foodborne pathogens transmission into the population $[8,11,16]$. Biofilms, defined as tri-dimensional communities of bacteria surrounded by extra-polymeric substances, such as polysaccharides, proteins, lipids, and DNA, are regarded as an important virulence factor in food processing environment. Previous studies have demonstrated that biofilms are less susceptible to sterilization procedures, such as sanitizers, than their planktonic counterparts [3, 5, 9]. Therefore, biofilm formation by foodborne pathogens increases the inefficiency of sterilization treatment $[4,13]$ and thus, the risk of pathogens transmission into the population.

Studying gene expression was shown to be an important analytic tool to be used as it allows us to evaluate how new sanitizers impact the virulence of foodborne bacterial strains [17]. In order to assess specific changes in the bacterial physiology, the correct quantification of specific messenger RNA (mRNA) from bacterial biofilms is an important requirement. Currently, there are plenty of different RNA extraction kits available, and it has been shown that distinct kits can yield RNA with different levels of quality. This can be due to inherent characteristics of the kit and/or due to the nature of the sample [7, 14, 19]. Biofilms are communities of bacteria embedded on extracellular matrix, which is estimated to comprise up to $90 \%$ of the total biofilm biomass [6]. Polysaccharides, one of the major components of many bacterial biofilm matrices, seems to difficult the bacterial cell lysis and the nucleic acids, once purified, may still contain inhibitory substances that will influence the accuracy and reproducibility of mRNA quantification $[10,20]$. Therefore, the aim of this study was to compare the performance of five 
commercially available RNA extraction kits, namely; FastRNA $^{\circledR}$ Pro Blue (MP Biomedicals, Irvine, CA, US), Illustra RNAspin Mini (GE Healthcare, Upsala, Sweden), PureZOL $^{\mathrm{TM}}$ RNA isolation reagent (Bio-Rad, Hercules, CA, US), PureLink ${ }^{\mathrm{TM}}$ RNA Mini Kit (Invitrogen, San Diego, CA, US), and GenJET ${ }^{\mathrm{TM}}$ (Fermentas, Ontario, Canada) using samples from the biofilm-forming foodborne pathogens L. monocytogenes, E. coli, and S. enterica.

\section{Materials and Methods}

Bacteria and Biofilm Formation Conditions

In this study, three different foodborne biofilm-forming bacteria were used: L. monocytogenes CECT 4031T, E. coli K12 substrain MG 1655, and S. enterica serovar enteritidis NCTC 13349. Bacterial biofilms were grown as previously described $[2,17]$. In brief, one single colony of L. monocytogenes was inoculated in $2 \mathrm{~mL}$ Tryptic Soy Broth (TSB) (Oxoid, Cambridge, UK), and E. coli and S. enterica in Luria-Bertani (LB) Broth (Merck, NJ, US) from Tryptic Soy Agar plates not older than 2 days and grown at $37{ }^{\circ} \mathrm{C}$ in a shaker rotator at $120 \mathrm{rpm}$ for 24 $( \pm 2) \mathrm{h}$. Then, 1:200 dilution was performed in fresh TSB and incubated in a 24-well plate (Orange Scientific, BraineL'Alleud, Belgium) at $37{ }^{\circ} \mathrm{C}, 100 \mathrm{rpm}$ for $24( \pm 2) \mathrm{h}$. Biofilms were washed with $0.9 \% \mathrm{NaCl}$ to remove planktonic cells before RNA extraction. Biofilm biomass was quantified by optical density (OD) at $595 \mathrm{~nm}$ by the crystal violet staining method as described before [2]. This experiment was performed in triplicates.

\section{RNA Extraction and Quality}

Total RNA was isolated according to the manufacturer's instructions, with the following optimization: when appropriated, enzymatic lysis was performed during $60 \mathrm{~min}$ at $37{ }^{\circ} \mathrm{C}$ with $15 \mathrm{mg} / \mathrm{mL}$ of lysozyme. The RNA extraction kits were selected based on their different extraction principles: organic extraction with mechanical and chemical lysis (FastRNA ${ }^{\circledR}$ ProBlue (MP Biomedicals)), organic lysis with enzymatic lysis (PureZOL ${ }^{\mathrm{TM}}$ RNA isolation reagent (Bio-Rad)), and silica membrane extraction with enzymatic lysis (Illustra RNAspin Mini (GE Healthcare), PureLink ${ }^{\mathrm{TM}}$ RNA Mini Kit (Invitrogen), and GenJET $^{\mathrm{TM}}$ (Fermentas)). The final RNA fraction was obtained by suspending or eluting in $45 \mu \mathrm{L}$ of RNase free water. To digest possible contaminating genomic DNA, DNase I (Fermentas) treatment was performed by following the manufacturer's instructions. In brief, $5 \mu \mathrm{L}(10 \times)$ of reaction buffer and $2 \mu \mathrm{L}$ DNase I were added to the extracted RNA and incubated at $37{ }^{\circ} \mathrm{C}$ for $30 \mathrm{~min}$. After that, $5 \mu \mathrm{L}$ of $25 \mathrm{mM}$ EDTA was added and incubated at $65{ }^{\circ} \mathrm{C}$ for $10 \mathrm{~min}$ to inactivate the DNase I enzyme. RNA yield $(\mathrm{ng} / \mu \mathrm{L})$ and purity $\left(\mathrm{A}_{260} / \mathrm{A}_{280}\right.$ and $\left.\mathrm{A}_{260} / \mathrm{A}_{230}\right)$ were determined using a NanoDrop $1000^{\mathrm{TM}}$ (Thermo Scientific, MA, US). RNA integrity was verified by loading the samples in a $1 \%$ agarose gel run at $80 \mathrm{~V}$ for $60 \mathrm{~min}$ and stained with ethidium bromide. Gels were visualized using a GelDoc2000 (Bio-Rad). RNA samples were stored at $-80{ }^{\circ} \mathrm{C}$ for further analyses. Each RNA extraction was performed two to four times.

\section{Quantitative Real Time-PCR (qPCR)}

For the quantification of gene expression by qPCR, total RNA was reverse transcribed to complementary DNA (cDNA) using iScript ${ }^{\mathrm{TM}}$ cDNA Synthesis Kit (Bio-Rad) following the manufacturer's instructions. In brief, $7.5 \mu \mathrm{L}$ of total RNA was mixed with $2 \mu \mathrm{L}$ iScript reaction buffer $(5 \times)$ and $0.5 \mu \mathrm{L}$ of reverse transcriptase. The samples were incubated at $25{ }^{\circ} \mathrm{C}$ for $5 \mathrm{~min}, 42{ }^{\circ} \mathrm{C}$ for $30 \mathrm{~min}$, and $85{ }^{\circ} \mathrm{C}$ for $5 \mathrm{~min}$. Oligonucleotide primers for the amplification of 16S rRNA, a housekeeping gene, and specific virulence genes of each bacterium tested (Table 1) were designed using Primer3 software [18] using as templates the genomes with the following accession numbers CP002816.1, NC_013353.,1, and AM933172.1. Primers efficiency was determined by the dilution method and using a temperature

Table 1 Sequences of the oligonucleotide primers used for qPCR amplification assay:

\begin{tabular}{|c|c|c|c|c|c|c|}
\hline Bacterial species & Gene & Forward & Reverse & $\mathrm{Tm}$ & $\begin{array}{l}\text { Amplicon } \\
\text { size }\end{array}$ & $\begin{array}{l}\text { Forwarc } \\
\text { priming } \\
\text { position }\end{array}$ \\
\hline \multirow[t]{2}{*}{ L. monocytogenes } & $16 S$ & GGAGCATGTGGTTTAATTCG & CCAACTAAATGCTGGCAACT & $58.1 / 57.9$ & 199 & 945 \\
\hline & $\operatorname{prfA}$ & GGTAGCCTGTTCGCTAATGA & TAACCAATGGGATCCACAAG & $58.0 / 58.2$ & 193 & 437 \\
\hline \multirow[t]{2}{*}{ E. coli } & $16 S$ & CGGACGGGTGAGTAATGTCT & TCAGACCAGCTAGGGATCGT & $59.9 / 59.8$ & 193 & 106 \\
\hline & tyr $B$ & CGTCAGGAATTGGTGAAGGT & TGGCGATGAGATAGACACCA & $59.9 / 60.2$ & 151 & 967 \\
\hline \multirow[t]{2}{*}{ S. enterica } & $16 S$ & CAGAAGAAGCACCGGCTAAC & GACTCAAGCCTGCCAGTTTC & $60.0 / 60.0$ & 167 & 493 \\
\hline & $r p o S$ & GAATCTGACGAACACGCTCA & CCACGCAAGATGACGATATG & $59.9 / 60.1$ & 171 & 79 \\
\hline
\end{tabular}

The theoretical melting temperature $(\mathrm{Tm})$, the amplicon size, and the priming position within the gene are indicated. 
gradient. At the selected annealing temperatures the primer-pairs had equivalent priming efficiencies. Two microliters of each primer-pair, at $10 \mu \mathrm{M}$, were added to $10 \mu \mathrm{L}$ of $(2 \times)$ SsoFast $^{\mathrm{TM}}$ EvaGreen supermix (Bio-Rad), $6 \mu \mathrm{L}$ of RNAse-free water, and $2 \mu \mathrm{L}$ of 1:20 cDNA dilution. The experiment was performed in $\mathrm{CFX} 96^{\mathrm{TM}}$ real time PCR system (Bio-Rad) using the following cycling parameters; $30 \mathrm{~s}$ at $94{ }^{\circ} \mathrm{C}$ followed by 40 repeats of $5 \mathrm{~s}$ at $94{ }^{\circ} \mathrm{C}, 10 \mathrm{~s}$ at $53{ }^{\circ} \mathrm{C}$ (for L. monocytogenes primers), or $50{ }^{\circ} \mathrm{C}$ (for S. enterica primers), or $60{ }^{\circ} \mathrm{C}$ (for E. coli primers), and finally $15 \mathrm{~s}$ at $72{ }^{\circ} \mathrm{C}$. Neither unspecific product nor primer dimer formation was observed in the melting curves. The absence of genomic DNA contamination was assessed by including a control where the reverse transcriptase reaction did not occur. The cycle threshold $(\mathrm{Ct})$ detection of each gene was determined using the standards parameters of the software. The gene expression quantification was plotted using the $\mathrm{Ct}$ values obtained by each RNA extraction kits/bacterial combination. The linearity $\left(r^{2}\right)$ of gene expression quantification was then determined assuming a linear regression. The qPCR was performed two times with triplicates.

\section{Statistical Analysis}

All the assays were compared using one-way analysis of variance (ANOVA) with Tukey multiple comparisons test and also the unpaired sample $t$ test, using SPSS software (Statistical Package for the Social Sciences). Student's $t$ test was applied to all the experimental data for the rejection of some experimental values. All tests were performed with a confidence level of $95 \%$.

\section{Results and Discussion}

\section{Biofilm Formation Quantification}

The purpose of this study was to compare the performance of different RNA extraction methods using bacterial biofilms. Considering that initial amount of bacterial cells used for RNA extraction will impact, at some extent, the total RNA quantity, it is important to quantify the biofilms used for RNA extraction. However, the relationship between amount of sample and RNA yield is not completely linear, and each kit normally has an optimal range of sample concentration. In a comparison study using several different RNA extraction kits in rabbit blood samples, it was found that, in one of the extraction kits used, too much concentrated sample would result in lower RNA yields. Still, the majority of the cases reported indicated that a lower initial sample concentration would result in lower yields of RNA [14]. The amount of biofilm formed

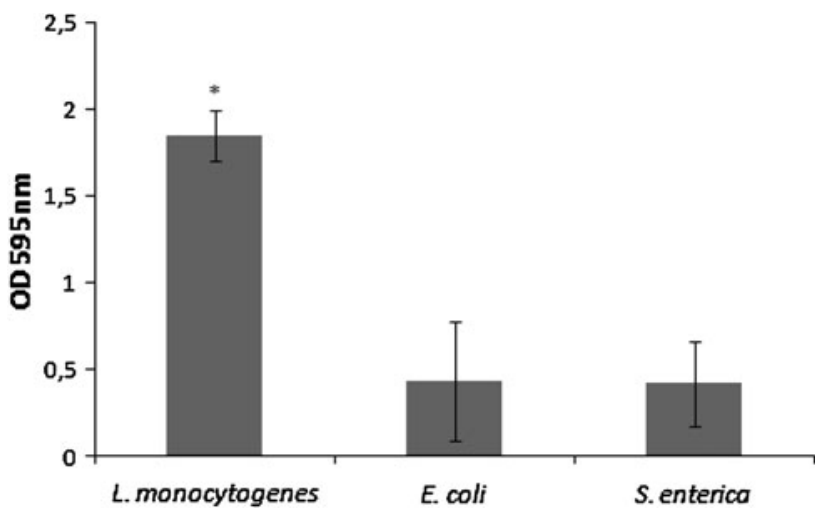

Fig. 1 Biofilm quantification by crystal violet staining method. The bars and the points represent the mean plus or minus standard deviation of three independent experiments with eight different biofilms per experiment (* statistically significant $P<0.05$ )

by each strain is presented in Fig 1. L. monocytogenes was clearly the strain with a thicker biofilm (OD $595 \mathrm{~nm} \approx 2$ ), while $E$. coli and $S$. enterica formed thinner biofilms (OD $595 \mathrm{~nm} \approx 0.5$ ), that were easily detached from the surface. Due to the intrinsic differences in bacterial species biofilm formation ability and matrix composition, we did not compare the performance of the RNA extraction kits between the different organisms.

As our experiments aimed to study the outcome of RNA quality in gene expression quantification inside bacterial biofilm communities, and as most biofilms cells show distinct mRNA expression profile depending on the region of the biofilm [23], we did not try to further explore a possible optimization of the process using lower cell concentration, as this could potentially result in high variability from one biological replicate to another.

RNA Yield, Purity, and Integrity

When determining the RNA quality, a few parameters such as RNA yield, purity, and integrity are normally considered [1]. Despite of the inherent factors related with each specific RNA extraction kits, the samples can present intrinsic properties that can lead to the extraction of different quantities and qualities of RNA. Although for many applications the minimum required quantity of RNA can be relatively low, when the aim of the experiment is to detect low expressing genes, a reduced yield of extraction could place these genes below the limit of detection. Thus, RNA quantity is one important requirement to consider when choosing a proper RNA extraction kit. A known issue regarding RNA yield is related with the increased difficulty in lysing Gram-positive bacteria [7]. According to the manufacturer instructions, aiming to optimize the RNA extraction of Gram-positive bacteria, we increased the concentration of lysozyme to $15 \mathrm{mg} / \mathrm{mL}$ as well as the lysis 
step for $60 \mathrm{~min}$. This optimization increases the yield of total RNA from two to fourfold (data not shown). Interestingly, for each of the bacterial species addressed in this study, a different kit resulted in higher RNA quantity: PureLink $^{\mathrm{TM}}$ was the best kit for E. coli $(240 \mathrm{ng} / \mu \mathrm{L})$, Illustra RNAspin for $S$. enterica $(140 \mathrm{ng} / \mu \mathrm{L})$, and Fast$\mathrm{RNA}^{\circledR}$ for L. monocytogenes $(274 \mathrm{ng} / \mu \mathrm{L}$ ) (Fig. 2).

Besides the importance of the quantity, the sample purity is another important requirement in RNA extraction procedures, since the presence of inhibitory compounds can influence the accuracy of the downstream applications [12]. The RNA purity is usually evaluated by determining the absorbance ratios $A_{260} / A_{280}$ and $A_{260} / A_{230}$ [18]. Pure RNA is expected to have the referred ratios above 1.8. An $\mathrm{A}_{260} / \mathrm{A}_{280}$ lower than 1.8 indicates the presence of protein
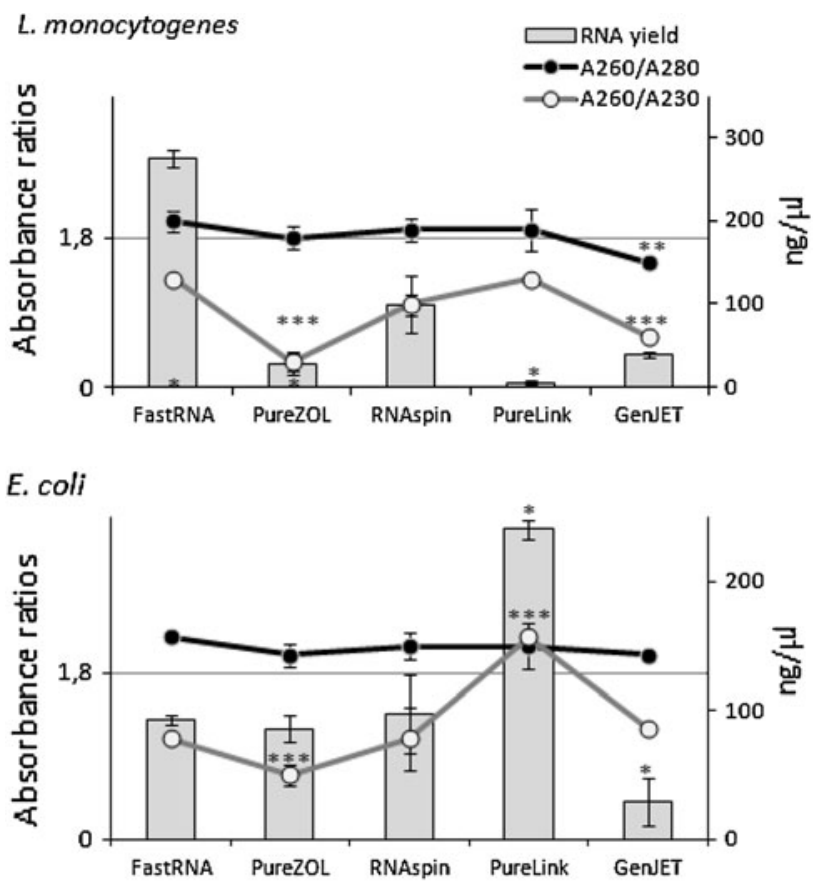

\section{S. enterica}

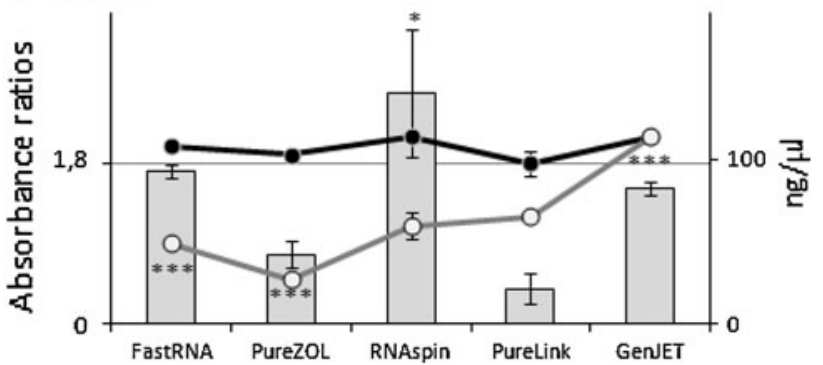

Fig. 2 Comparison of the RNA yield and purity following different RNA extraction procedures. The bars and the points represent the mean plus or minus standard deviation of two independent experiments (*RNA yield, $* * \mathrm{~A}_{260} / \mathrm{A}_{280}$ or $* * * \mathrm{~A}_{260} / \mathrm{A}_{230}$ statistically significant $P<0.05)$. contamination while, an $\mathrm{A}_{260} / \mathrm{A}_{230}$ lower than 1.8 indicates the presence of polysaccharides from the biofilm matrix, and/or other inhibitory compounds, such as phenol and chaotropic salts, possibly introduced during RNA extraction procedure [24]. When working with complex microbial communities such as biofilm, RNA purity is often impaired mainly due to the presence of the biofilm matrix components, such as proteins and polysaccharides [7]. In general, all the RNA extraction kits/bacteria combinations presented an $\mathrm{A}_{260} / \mathrm{A}_{280}$ ratio between the ranges accepted for pure RNA. The only exception was the kit from Gen$\mathrm{JET}^{\mathrm{TM}}$ in $L$. monocytogenes where the values were under 1.8 (Fig. 2). On the other hand, regarding the $\mathrm{A}_{260} / \mathrm{A}_{230}$ ratio results, we observed that most of the kits used, especially PureZOL ${ }^{\mathrm{TM}}$, were ineffective removing the polysaccharides from the biofilm samples and/or other inhibitory compounds during RNA extraction procedure. The only exceptions were PureLink ${ }^{\mathrm{TM}}$ in E. coli and GenJET $^{\mathrm{TM}}$ in $S$. enterica (Fig. 2) that showed $\mathrm{A}_{260} / \mathrm{A}_{230}$ above 1.8 .

The issue of RNA integrity was assessed by the visualization of the $23 \mathrm{~S}$ and $16 \mathrm{~S}$ pattern bands on an agarose gel, as determined by the absence of RNA smearing and by the double intensity of the $23 \mathrm{~S}$ regarding $16 \mathrm{~S}$ band [15]. Although this is the most common method used to assess the integrity of total RNA, it has some drawback, namely the sensitivity of the assay. On a technical note released by Invitrogen (Is Your RNA Intact? Methods to Check RNA Integrity) was stated that the limit of detection of RNA in an ethidium bromide stained agarose gel was $200 \mathrm{ng}$. However, this limit needs to be determined experimentally, as the qualities of the detector and ethidium bromide will affect the outcome. With our equipment and experimental setup, we could only detect RNA with at least $1 \mu \mathrm{g}$ of RNA. Therefore, RNA integrity was not determined in L. monocytogenes RNA obtained by PureLink ${ }^{\mathrm{TM}}$. With the exception of PureZOL ${ }^{\mathrm{TM}}$, all other kits extracted RNA with good integrity (data not shown).

\section{RNA Functionality and Gene Expression}

Many other research groups have shown similar studies when addressing the optimization of RNA extraction in different biological samples $[10,14,19,20]$. However, in such studies, normally they only report the resulted RNA physical characteristics such as the concentration, purity, and integrity after different extraction methods. Of upmost importance is to compare the outcome of such physical characteristics in the gene expression quantification. Therefore, to further address the issue of RNA quality and to determine if the RNA extracted was functional, total RNA was reverse transcribed into cDNA and quantified by qPCR. On an extensive study regarding the optimization of 
eukaryotic cDNA synthesis using commercially available kits, it was found that, when using cDNA synthesized with $40-5000$ ng of total RNA, there was no significant gene expression variation. However, when using lower concentrations of total RNA, a high variability of gene expression was found [22]. This can be partially explained by the fact that RNA extracted is composed of 1-5\% of mRNA, the rest being rRNA and tRNA. As mRNA is highly unstable, with half-life in the range of a few minutes, when total RNA yield is very low, some of the specific mRNA can be lost. As a lot less mRNA exists, a small lost can significantly change the outcome of a genetic expression analysis particularly, when small differences in gene expression are being studied. Another possible explanation for these results can be the high sensitivity of qPCR to small amounts of inhibitors in the RNA sample [12].

In order to analyze if the RNA's extracted by different kits would impact the gene expression quantification, $7.5 \mu \mathrm{L}$ of total RNA, resulting in RNA quantity between the range proposed by Sieber et al. [22], was reverse transcribed into cDNA and then quantified by qPCR, using the primers listed in Table 1. The overall results demonstrated that all the kits tested produced functional mRNA, as both housekeeping and virulence genes were detected, despite the differences observed in the quantity and purity (Fig. 2). Accordingly to Sieber et al. [22], it could be expected that the relationship between housekeeping and virulence gene (known as normalized gene expression) within the same biofilm/bacteria would be constant, since each bacterial biofilm was grown in the same conditions. While for $S$. enterica this was true $\left(r^{2}=0.97\right)$, the same did not occur in the other two bacterial biofilms (E. coli $r^{2}=0.65$ and L. monocytogenes $r^{2}=0.63$ ) (Fig. 3). Analyzing carefully the $E$. coli curve, if we exclude the data obtained by the RNA extracted with PureZOL ${ }^{\mathrm{TM}}$, the linearity would be higher $\left(r^{2}=0.97\right)$. As PureZOL ${ }^{\mathrm{TM}}$ was extracted with sufficient yield (Fig. 2) to be detected by the

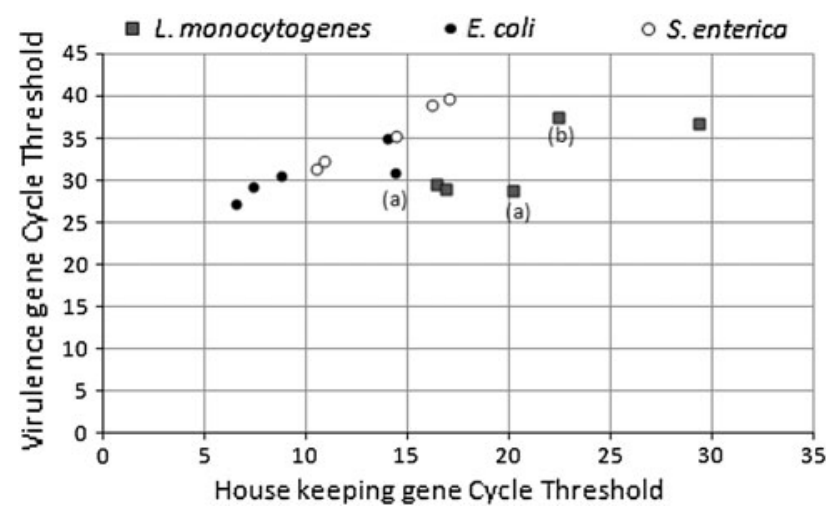

Fig. 3 Gene expression determined from RNA extracted with the different kits. Each point is the average of two independent experiments. The standard deviations are less than $1 \mathrm{Ct}$. agarose gel, we were able to verify that the extracted RNA was not stable confirming, therefore, the crucial role of the RNA integrity in mRNA quantification. The same result was observed with $L$. monocytogenes, and this can explain the lower detection of the virulence genes. Nevertheless, in the case of L. monocytogenes RNA extracted with PureLink $^{\mathrm{TM}}$, we cannot conclude that the variation observed was due to lack of RNA integrity, since the concentration of RNA obtained was lower than the limit of detection.

\section{Conclusions}

From our results, we can infer that while the RNA extracted by the different kits was functional as cDNA source, as each gene was detected in the qPCR experiment, the outcome of the gene expression quantification was affected by the lower RNA quality. Interestingly, most kits yielded RNA with no protein contamination, but with some level of polysaccharides, phenol, or chaotropics salts contamination. However, no relationship was found regarding the RNA purity and the variability in gene expression. The same was true for the RNA yield. On the other hand, RNA integrity seemed to be the only factor that impacts directly in the stability of gene expression. Recently, it has been proposed that RNA purity and yield quality indicators were neither sufficient nor straightforward as to determine the stability of gene expression [12]. Therefore, it seems clear that a wrong RNA extraction kit selection can have an important impact on genetic expression quantification in biofilms. Moreover, the choice for an RNA extraction kit will most definitively be related to the bacterial species and the composition of the biofilm matrix [7] used as these characteristics impact in the quality of the RNA extracted and thus, in an accurate gene expression quantification.

Acknowledgments $\mathrm{AF}$ and JCB acknowledge the financial support of individual grants SFRH/BD/62359/2009 and SFRH/BD/66250/ 2009 , respectively. The authors acknowledge the gift of bacterial strains to Joana Azeredo and Maria Olivia Pereira.l

Conflict of interest The author(s) declare that they have no conflict of interests.

\section{References}

1. Bustin SA, Benes V, Nolan T, Pfaffl MW (2005) Quantitative real-time RT-PCR-a perspective. J Mol Endocrinol 34:597-601

2. Cerca N, Jefferson KK (2008) Effect of growth conditions on poly-N-acetylglucosamine expression and biofilm formation in Escherichia coli. FEMS Microbiol Lett 283:36-41

3. Chavant P, Gaillard-Martinie B, Hebraud M (2004) Antimicrobial effects of sanitizers against planktonic and sessile Listeria monocytogenes cells according to the growth phase. FEMS Microbiol Lett 236:241-248 
4. Djordjevic D, Wiedmann M, McLandsborough LA (2002) Microtiter plate assay for assessment of Listeria monocytogenes biofilm formation. Appl Environ Microbiol 68:2950-2958

5. Fatemi P, Frank JF (1999) Inactivation of Listeria monocytogenes/Pseudomonas biofilms by peracid sanitizers. J Food Prot 62:761-765

6. Flemming HC, Wingender J (2010) The biofilm matrix. Nature 8:623-633

7. Franca A, Melo L, Cerca N (2011) Comparison of RNA extraction methods from biofilm samples of Staphylococcus epidermidis. BMC Res Notes 4:572

8. Jessen B, Lammert L (2003) Biofilm and disinfection in meat processing plants. Int Biodeterior Biodegrad 51:265-269

9. Joseph B, Otta SK, Karunasagar I, Karunasagar I (2001) Biofilm formation by salmonella spp. on food contact surfaces and their sensitivity to sanitizers. Int J Food Microbiol 64:367-372

10. Junttila S, Lim KJ, Rudd S (2009) Optimization and comparison of different methods for RNA isolation for cDNA library construction from the reindeer lichen Cladonia rangiferina. BMC Res Notes 2:204

11. Lewis SJ, Gilmour A (1987) Microflora associated with the internal surfaces of rubber and stainless steel milk transfer pipeline. J Appl Bacteriol 62:327-333

12. Lloyd KG, Macgregor BJ, Teske A (2010) Quantitative PCR methods for RNA and DNA in marine sediments: maximizing yield while overcoming inhibition. FEMS Microbiol Ecol 72:143-151

13. Mangalappalli-Illathu AK, Lawrence JR, Swerhone GD, Korber DR (2008) Architectural adaptation and protein expression patterns of Salmonella enterica serovar enteritidis biofilms under laminar flow conditions. Int J Food Microbiol 123:109-120

14. Nour AM, Barbour EK, Depint F, Dooms M, Niang K, Dulac A, Niamba CN, Chaaya G, Pouillart PR (2010) Comparison of five RNA extraction methods from rabbit's blood. Agric Biol J N Am $1: 448-450$
15. Pinto FL, Thapper A, Sontheim W, Lindblad P (2009) Analysis of current and alternative phenol based RNA extraction methodologies for cyanobacteria. BMC Mol Biol 10:79

16. Reij MW, Den Aantrekker ED (2004) Recontamination as a source of pathogens in processed foods. Int $\mathrm{J}$ Food Microbiol 91:1-11

17. Rodrigues D, Cerca N, Teixeira P, Ceri H, Oliveira R, Azeredo J (2011) Listeria monocytogenes and Salmonella enterica enteritidis biofilms susceptibility to different disinfectants and stress response and virulence gene expression of surviving cells. Microb Drug Resist 17(2):181-189

18. Rozen S, Skaletsky H (2000) Primer3 on the WWW for general users and for biologist programmers. In: Krawetz S, Misenser S (eds) Methods in molecular biology. Humana Press, Totowa, pp 365-386

19. Rump LV, Asamoah B, Gonzalez-Escalona N (2010) Comparison of commercial RNA extraction kits for preparation of DNAfree total RNA from salmonella cells. BMC Res Notes 3:211

20. Santiago-Vázquez LZ (2006) Comparison of two total RNA extraction protocols using the marine gorgonian coral Pseudopterogorgia elisabethae and its symbiont Symbiodinium sp. Electron J Biotechnol 9:598-603

21. Scallan E, Hoekstra RM, Angulo FJ, Tauxe RV, Widdowson MA, Roy SL, Jones JL, Griffin PM (2011) Foodborne illness acquired in the United States-major pathogens. Emerg Infect Dis 17:7-15

22. Sieber MW, Recknagel P, Glaser F, Witte OW, Bauer M, Claus RA, Frahm C (2010) Substantial performance discrepancies among commercially available kits for reverse transcription quantitative polymerase chain reaction: a systematic comparative investigator-driven approach. Anal Biochem 401:303-311

23. Stewart PS, Franklin MJ (2008) Physiological heterogeneity in biofilms. Nat Rev Microbiol 6:199-210

24. Tavares L, Alves PM, Ferreira RB, Santos CN (2011) Comparison of different methods for DNA-free RNA isolation from SK-N-MC neuroblastoma. BMC Res Notes 1:140 